\title{
A 14-yr-old male with dyspnoea, productive cough and chest pain
}

\author{
G.A. Rossi*, P. Tomà ${ }^{\#}$, O. Sacco*, B. Fregonese*, E. Podestà", P. Dodero", G. Silvestri+, C. Gambini§
}

\section{Case history}

A 14-yr-old White male was referred to the Urology Unit of the G. Gaslini Institute because of a post-traumatic urethral stenosis (arising from a bicycle accident) that, during the previous 18 months, had required repeated endoscopic urethral dilation manoeuvres at the patient's local hospital. Apart from the urethral stenosis, the patient had been in excellent health until 2 months before admission, when slowly progressive exertional dyspnoea, associated with nonproductive cough and right-sided posterior chest pain, developed.

On admission, the patient appeared in good clinical condition. Decreased percussion and auscultatory sounds were noted over the middle and lower portions of the right hemithorax.

A summary of the results of the blood tests performed on admission is shown in table 1 .

Chest radiography (fig. 1) and high-resolution computed tomography (HRCT) (fig. 2) were performed.

Thoracocentesis was performed and $500 \mathrm{~mL}$ haemorrhagic pleural fluid aspirated.

Pleural fluid analysis did not show any cytological changes suggesting malignancies, amylase levels were within the normal

Table 1.-Results of blood tests performed on admission

\begin{tabular}{lc}
\hline Haemoglobin $\mathrm{g} \cdot \mathrm{L}^{-1}$ & 110 \\
White blood cell count $10^{9}$ cells $\cdot \mathrm{L}^{-1}$ & 10.1 \\
Platelet count $10^{9}$ cells $\cdot \mathrm{L}^{-1}$ & 684.0 \\
Erythrocyte sedimentation rate $\mathrm{mm} \cdot \mathrm{h}^{-1}$ & 102 \\
C-reactive protein $\mathrm{g} \cdot \mathrm{L}^{-1}$ & 4.7 \\
Serum protein & Normal \\
Immunoglobulin electrophoresis & Normal \\
Creatinine $\mu \mathrm{M}$ & 80 \\
ANA, ANCA & Negative \\
Rheumatoid factor $\mathrm{kIU} \cdot \mathrm{L}^{-1}$ & $<80$ \\
Cold agglutinin & Negative \\
Complement component $3 \mathrm{~g} \cdot \mathrm{L}^{-1}$ & 0.9 \\
Complement component $4 \mathrm{~g} \cdot \mathrm{L}^{-1}$ & 0.3 \\
Skin reactivity to recall antigens & Normal \\
Phagocytic oxidative metabolism & Normal \\
Tuberculin skin test & Negative \\
$P$ tc, $\mathrm{O}_{2}$ in room air $\mathrm{kPa}$ & 12.1 \\
$P$ tc, $\mathrm{CO}$ & in room air $\mathrm{kPa}$ \\
Blood/pharyngeal aspirate/urine stain and culture & 4.9 \\
& Negative
\end{tabular}

ANA: antinuclear antibody; ANCA: antineutrophilic cytoplasmic antibody; $P$ tc, $\mathrm{O}_{2}$ : transcutaneous oxygen tension; $P$ tc, $\mathrm{CO}_{2}$ : transcutaneous carbon dioxide tension. range and microbiological evaluation results were negative for bacteria, fungi, mycoplasmata, mycobacteria and viruses. Plasma D-dimer levels were slightly elevated but ultrasonography of the deep venous system did not show signs of thrombosis in the legs, penis or pelvis.

Echocardiographic evaluation did not demonstrate any right ventricular dysfunction.

Ultrasonographic examinations showed that there were no abnormalities of the abdominal organs and no peritoneal effusion and ruled out the presence of testicular or thyroid tumours.

Fibreoptic bronchoscopy was then performed and did not reveal any airway abnormalities. Bronchoalveolar lavage analysis was nondiagnostic (no siderocytes suggestive of pulmonary haemorrhage, acid-fast bacilli, bacteria, viruses, fungi or malignant cells were identified in the epithelial lining fluid or lavage fluid cells).

Thoracoscopy to obtain lung tissue biopsy specimens and pleurodesis were then performed and the removed specimens sent to a pathologist for morphological evaluation of pleural (fig. 3) and lung tissues (fig. 4).

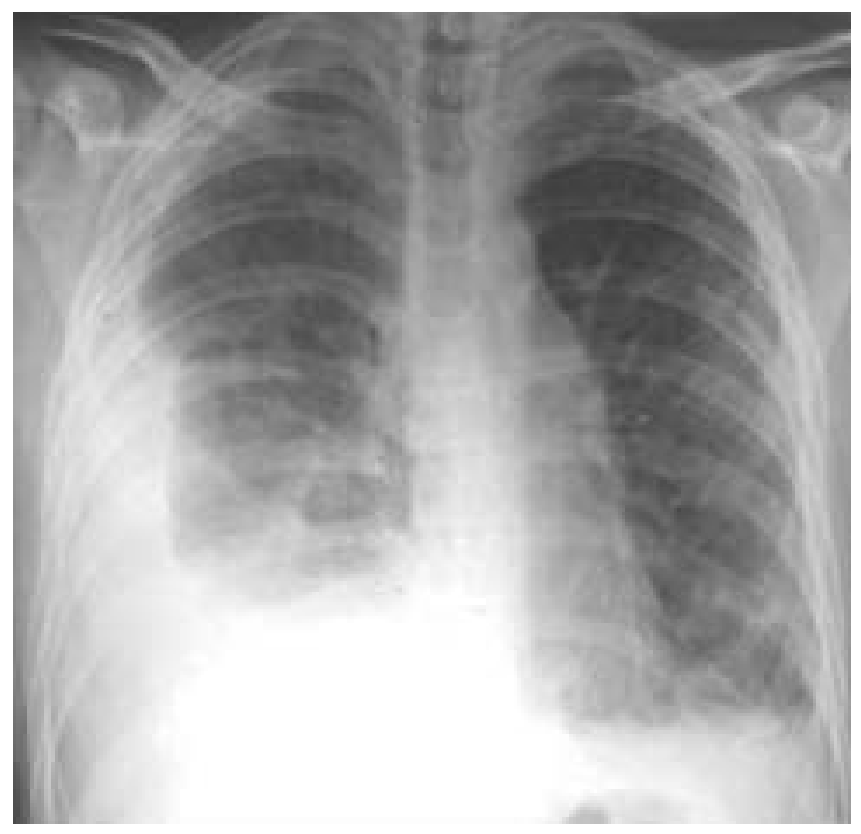

Fig. 1.-Chest radiograph.

Depts of *Pulmonology, ${ }^{*}$ Radiology, ${ }^{\text {`Surgery, }}{ }^{+}$Anaesthesiology and Intensive Care, and ${ }^{\S}$ Service of Pathology, G. Gaslini Institute, Genoa, Italy. Correspondence: G.A. Rossi, Dept of Pulmonology, G. Gaslini Institute, Largo G. Gaslini 5, 16147 Genoa, Italy. Fax: 39 0103776590. E-mail: giovannirossi@ospedale-gaslini.ge.it 

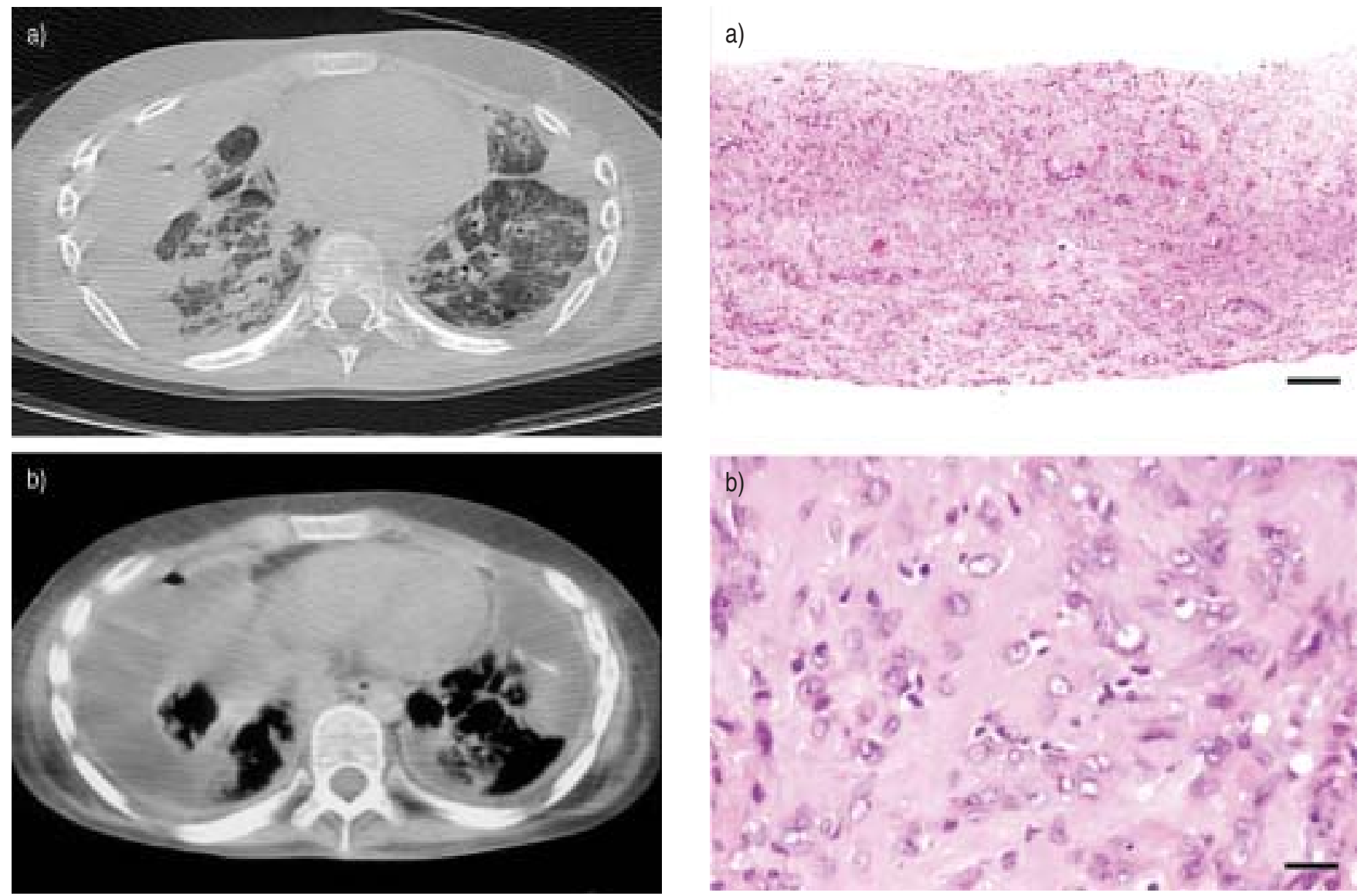

Fig. 2. - High-resolution computed tomography of the chest at two different window settings: a) "parenchymal"; and b) "soft tissue".

Fig. 3.- Pleural biopsy specimens. Haematoxylin and eosin stain; internal scale bar= a) $175 \mu \mathrm{m}$, b) $25 \mu \mathrm{m}$. 

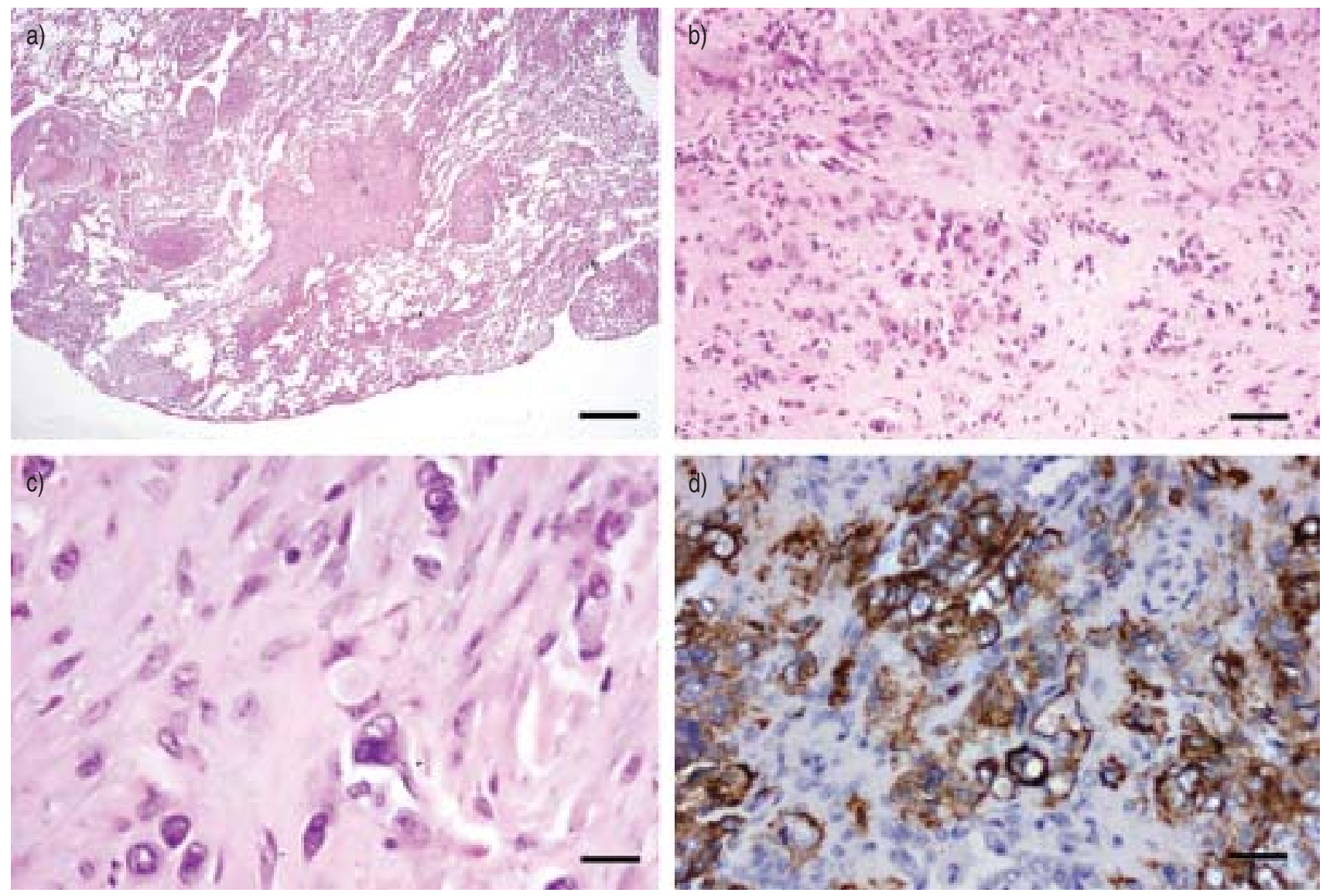

Fig. 4. - Lung biopsy specimens. Haematoxylin and eosin stain (a-c) internal scale bar= a) $1 \mathrm{~mm}$, b) $50 \mu \mathrm{m}$, c) $25 \mu \mathrm{m}$. Anti-CD34 monoclonal antibody immunostaining (d) internal scale bar $=25 \mu \mathrm{m}$.

BEFORE TURNING THE PAGE, INTERPRET THE RADIOGRAPH, COMPUTED TOMOGRAPHY SCANS AND HISTOPATHOLOGICAL RESULTS AND SUGGEST A DIAGNOSIS AND TREATMENT. 


\section{Interpretation}

\section{Chest radiography}

Posteroanterior chest radiography revealed patchy opacities in the middle/lower lung fields and uniform meniscusshaped opacification of the lower and the lateral portions of the right hemithorax, suggesting the presence of pleural effusion (fig. 1). Obliteration of the costophrenic sinus was also present contralaterally, suggesting the presence of a smaller amount of fluid in the left pleural cavity. No hilar or mediastinal lymph node enlargement could be observed.

\section{Computed tomography}

HRCT of the thorax revealed, in addition to bilateral pleural thickening and effusion, multiple ill-defined interstitial and nodular lesions with soft tissue thickening extending from the subpleural regions and from the hilum, not always along the bronchovascular structures (fig. 2).

\section{Diagnostic considerations}

In the differential diagnosis of the present case, the following diagnoses were considered: 1) chronic pulmonary embolisation of fibrin thrombi or foreign material; 2) vasculitis or collagen vascular diseases involving the lung and pleural tissues; 3) idiopathic bronchiolitis obliterans with organising pneumonitis; 4) lymphomas and angioinvasive lymphoproliferative disorders; 5) infections; 6) pleuropulmonary localisation of an extrathoracic tumour; 7) bronchioalveolar carcinoma; 8) epithelioid haemangioendothelioma; and 9) malignant mesothelioma.

\section{Surgical procedure and interpretation of surgical specimens}

Right-sided thoracoscopy was performed and multiple biopsy specimens obtained. The removed tissue was fixed and, to exclude infections, Ziehl-Neelsen, Gomori's methenamine silver, periodic acid/Schiff, Brown-Brenn and Dieterle's stains were performed. Elastic stains were also carried out to investigate possible vascular injury.

Histological examination of the biopsy specimens showed, at the pleural level (fig. 3a), diffuse fibrinofibrous pleuritis of up to $3 \mathrm{~mm}$ in thickness. Round neoplastic cells were observed in the fibrotic lesions on the visceral pleura (fig. 3b).

Evaluation of the lung tissue showed pulmonary nodules characterised by sclerotic and hypocellular centres (fig. 4a) and a midzone composed of neoplastic epithelioid and spindle cells, wedged between areas of sclerosis (fig. 4b). The epithelioid cells contained prominent intracytoplasmic vacuoles and few mitotic figures were observed (fig. 4c). Tests for markers of mesothelial, epithelial and muscular differentiation were all negative, whereas the positive staining with antibodies directed against vimentin, CD31 and CD34 (fig. 4d) confirmed the vascular endothelial origin of the tumour. There was a sparse lymphoplasmocytic infiltrate, with a few eosinophilic granulocytes and many iron-containing macrophages.
Diagnosis: Epithelioid haemangioendothelioma of the lung with pleural involvement

\section{Clinical course}

Within a few weeks after the diagnostic procedure, the patient's clinical condition deteriorated with progressive worsening of the dyspnoea; a clinically relevant left-sided serosanguineous pleural effusion developed and was treated with chemical pleurodesis. The patient's parents denied consent for chemotherapy with carboplatin and etoposide. Pulmonary function progressively deteriorated (forced vital capacity $12 \%$ of predicted value; forced expiratory volume in one second $13 \%$ pred) and HRCT of the thorax demonstrated marked progression of the pulmonary lesions and massive bilateral pleural thickening. In an attempt to improve pulmonary function, surgical resection of right pleural tissue was performed with no improvement and the patient died because of restrictive respiratory failure $\sim 3$ months after the diagnosis had been established. Permission for autopsy was refused by the parents.

\section{Discussion}

Epithelioid haemangioendothelioma is a rare tumour originating from the vascular endothelial cells and characterised by an epithelioid or histiocytoid appearance [1-4]. It can be found in any organ but occurs most often in superficial or deep soft tissues of the extremities, the liver and the lung [1-4]. In the respiratory system, it was originally described by DAIL and LIEBOW [1], who named it "intravascular, bronchiolar and alveolar pulmonary tumour" or "IVAT" because its carcinomatous appearance and remarkable propensity to invade pulmonary vessels and small airways.

The majority of patients affected by pulmonary epithelioid haemangioendothelioma $(\mathrm{PEH})$ are females with an age at first examination ranging 7-76 yrs [5-7]. In the typical pulmonary forms, PEH presents as solitary or, more often, bilateral multiple small nodules localised in the lower lung zones that may be associated with parenchymal infiltrates and hilar or peripheral lymphadenopathy [8-10]. A pleuritis secondary to the pulmonary lesion can occur [5-8], whereas epithelioid haemangioendotheliomas confined to the serous membrane are extremely rare $[2,4]$. Only in a few cases does the tumour extensively involve the pleural cavities, closely resembling malignant mesothelioma [2, 4]. Patients with PEH may be asymptomatic, and the disease detected incidentally on radiographs, or complain of nonspecific symptoms, such as chest pain, dyspnoea and cough [2-5]. Haemoptysis, secondary to pulmonary haemorrhage and pulmonary hypertension have also been reported in patients with $\mathrm{PEH}$ [2-5].

The diagnosis of PEH is made on the basis of histological features and confirmed immunohistochemically [4, 9]. The distinctive histological features of PEH are: 1) the structure of the nodules (sclerotic and hypocellular centre, with neoplastic cells between areas of sclerosis in the midzone and proliferating tumour cells in the peripheral zone); 2) the presence of numerous well-formed vessels; and 3) multiple intracellular vacuoles. Mitotic figures do not always occur, but their presence is indicative of a poor prognosis. An inflammatory reaction may accompany the malignant lesions [4]. Negative results after staining with markers of mesothelial, epithelial and muscular differentiation associated with positive results for endothelial cell markers, such as antibodies directed against factor VIII, CD31 or CD34, may confirm the diagnosis [11].

Although aggressive forms, as in the present patient, have 
been described, the progression of $\mathrm{PEH}$ is usually slow, with long-term survivors, and partial spontaneous regression in number and size of pulmonary nodular lesions in patients not receiving either radiation or cytostatic therapy $[5,8-10,12$, 13]. The aggressive forms have often been described in patients with pleural involvement, with systemic spread and a rapid and fatal progression [5, 14]. Indeed, in a recent report involving 21 pulmonary cases with a mean follow-up period of 73 months, it was found that the presence of pleural effusion associated with fibrinous pleuritic lesions and extrapleural proliferation of tumour cells were features of a worse prognosis [5].

Pulmonary epithelioid haemangioendothelioma prognosis also depends on the extent and localisation of the lesions. In limited pulmonary forms, which usually progress slowly, surgical excision of the nodules seems to be appropriate and effective $[5,15]$. In the diffuse forms, several chemotherapy protocols, including the administration of a variety of cytostatic agents (mitomycin C, 5-fluorouracil, cyclosphosphamide, vincristine, tegafur or cisplatin, carboplatin, etoposide and vinorelbine) have been tried in patients with pulmonary epithelioid haemangioendothelioma with varying results, ranging from complete remission (one reported case after treatment with carboplatin/etoposide) [7] to transient response [8] and no beneficial effect [5], confirming its classic chemoresistance. Conflicting results have also been obtained with interferonalpha $[8,11,16]$. The presence of hormonal receptors in pulmonary epithelioid haemangioendothelioma has been reported in the literature [17] and may indicate that, as in lymphangioleiomyomatiosis, hormonotherapy could be a potential treatment in selected cases [18].

\section{References}

1. Dail D, Liebow A. Intravascular bronchioalveolar tumor. Am J Pathol 1975; 78: 6a-7a.

2. Weiss S, Enzinger F. Epithelioid hemangioendothelioma. Cancer 1982; 50: 970-981.

3. Lauffer JM, Zimmermann A, Krahenbuhl L, Triller J, Baer HU. Epithelioid hemangioendothelioma of the liver. Cancer 1996; 78: 2318-2327.

4. Weiss SW, Ishak KG, Dail DH, Sweet DE, Enzinger FM. Epithelioid hemangioendothelioma and related lesions. Semin Diagn Pathol 1986; 3: 259-287.

5. Kitaichi M, Nagai S, Nishimura $\mathrm{K}$, et al. Pulmonary epithelioid haemangioendothelioma in 21 patients, including three with partial spontaneous regression. Eur Respir J 1998; 12: 89-96.

6. Dail DH, Liebow AA, Gmelich JT, et al. Intravascular, bronchiolar and alveolar tumor of the lung (IVBAT). Cancer 1983; 51: 452-464.

7. Pinet C, Magnan A, Garbe L, Payan M-J, Vervloet D. Aggressive form of pleural epithelioid haemangioendothelioma: complete response after chemotherapy. Eur Respir $J$ 1999; 14: 237-238.

8. Case Records of the Massachusetts General Hospital. Weekly clinicopathological exercises. Case 6-2000. Hemoptysis in a 20-year-old man with multiple pulmonary nodules. $N$ Engl J Med 2000; 342: 572-578.

9. Bevelaqua F, Valensi Q, Hulnick D. Epithelioid hemangioendothelioma: a rare tumor with variable prognosis presenting as a pleural effusion. Chest 1988; 95: 665-666.

10. Mukundan G, Urban BA, Askin FB, Fishman EK. Pulmonary epithelioid hemangioendothelioma: atypical radiologic findings of a rare tumor with pathologic correlation. J Comput Assist Tomogr 2000; 24: 719-720.

11. Miettinen M, Lindemayer AE, Chaubal A. Endothelial cell markers CD31, CD34 and BNH9 antibody to $\mathrm{H}$ - and Y-antigens - Evaluation of their specificity and sensitivity in the diagnosis of vascular tumors and comparison with von Willebrand factor. Mod Pathol 1994; 7: 82-90.

12. Youssem S, Hochholzer L. Unusual thoracic manifestation of epithelioid hemangioendothelioma. Arch Pathol Lab Med 1987; 111: 459-463.

13. Miettinen M, Collan Y, Halttunen P, Maamies T, Vilkko P. Intravascular bronchioloalveolar tumor. Cancer 1987; 24712475.

14. Lin BT, Colby T, Gown AM, et al. Malignant vascular tumors of the serous membranes mimicking mesothelioma. A report of 14 cases. Am J Surg Pathol 1996; 20: 1431-1439.

15. De-Luca S, Sanguinetti CM, Bearzi I, Murer B. Intravascular bronchioloalveolar tumour. Eur Respir J 1990; 3: 346-348.

16. Roudier-Pujol C, Enjolras O, Lacronique J. Multicentric epithelioid hemangioendothelioma in partial remission with interferon treatment. Ann Dermatol Venereol 1994; 121: 898904.

17. Ohori NP, Yousem S, Sonmez-Alpan E, Colby TV. Estrogen and progesterone receptors in lymphangioleiomyomatosis, epithelioid hemangioendothelioma, and sclerosing hemangioma of the lung. Am J Clin Pathol 1991; 96: 529-535.

18. Rossi GA, Balbi B, Oddera S, Lantero S, Ravazzoni C. Response to treatment with an analog of the luteinizinghormone-releasing hormone in a patient with pulmonary lymphangioleiomyomatosis. Am Rev Respir Dis 1991; 143: 174-176. 